\title{
ASSÉDIO MORAL NA ATENÇÃO BÁSICA SEGUNDO OS PROFISSIONAIS DE ENFERMAGEM
}

\author{
MORAL HARASSMENT IN PRIMARY CARE ACCORDING TO NURSING PROFESSIONALS
}

ACOSO MORAL EN LA ATENCIÓN BÁSICA SEGÚN LOS PROFESIONALES DE ENFERMERÍA

\author{
Cristiani Garrido de Andrade ${ }^{1}$ \\ Jonathas David Mendes Leão ${ }^{2}$ \\ Isabelle Cristinne Pinto Costa ${ }^{3}$ \\ Fabiana Medeiros de Brito ${ }^{4}$ \\ Kamyla Félix Oliveira dos Santos ${ }^{5}$ \\ Solange Fátima Geraldo da Costa ${ }^{6}$
}

Resumo Objetivou-se investigar como os profissionais de enfermagem compreendem o assédio moral, bem como identificar essas situações vivenciadas pelos profissionais dessa área, suas causas e consequências para a saúde desses trabalhadores. Trata-se de uma pesquisa exploratória, de natureza qualitativa, da qual participaram 15 profissionais de enfermagem atuantes em unidades de saúde da família, da cidade de João Pessoa, na Paraíba. A coleta de dados foi realizada no período de abril a maio de 2013 e ocorreu mediante uma entrevista gravada. Os dados foram analisados por meio da técnica de análise de conteúdo. Da análise do material, emergiram três categorias: Assédio moral, conceito e características na visão dos profissionais de enfermagem; Comportamentos de assédio moral experimentados por profissionais de enfermagem; e Consequências do assédio moral. Conclui-se que o assédio moral é disseminado entre enfermeiros e técnicos de enfermagem, apesar de alguns profissionais discernirem o conceito dessa prática, sendo notória a prevalência do tipo descendente.

Palavras-chave enfermagem; atenção básica; trabalho.
Abstract This study aimed to investigate the view nursing professionals have of moral harassment and how to identify these situations as experienced by the professionals in this area, as well as their causes and consequences for these workers' health. This is a qualitative exploratory research study in which 15 nursing professionals working at family health facilities in the city of João Pessoa, state of Paraíba, Brazil took part. Data collection took place between April and May 2013 by means of a recorded interview. The data were analyzed using the content analysis technique. The analysis of the material revealed three categories: Moral harassment: Concept and characteristics from the nursing professionals' viewpoint; Moral harassment behaviors experienced by nursing professionals, and Consequences of the moral harassment. We conclude that moral harassment is widespread among nurses and nursing technicians, although some professionals understand the concept of this practice, and the prevalence of the descending type is notorious.

Keywords nursing; primary care; work. 


\section{Introdução}

O assédio moral é tão antigo quanto as relações trabalhistas, porém nunca houve tanta repercussão como nos dias atuais, não somente em países industrializados mas também em países em desenvolvimento. Os estudos sobre o tema iniciaram-se nos anos 1980, com Heinz Leymann, que, ao investigar diversos grupos profissionais, detectou a presença de um tipo de violência laboral que não era física, mas psíquica, e que foi denominada terrorismo psicológico ou psicoterror (Leymann, 1996a).

A expressão assédio moral também é conhecida como mobbing (molestar) nos Estados Unidos, na Itália, na Alemanha e na Escandinávia; na Inglaterra, utiliza-se o termo bullying (tiranizar); na França, harcèlement moral (assédio moral); na Espanha, psicoterror laboral, acoso moral (psicoterror laboral, assédio moral); e no Japão, murahachibu, ijime (ostracismo social), entre outras denominações (Brodsky, 1976). Constituindo-se como um fenômeno social, a despeito das diferenças culturais, o assédio moral refere-se aos atentados contra a dignidade humana, ocorridos de forma intermitente, que podem manifestar-se na família, na escola ou no ambiente do trabalho (Aguiar, 2006; Caniato e Lima, 2008).

No Brasil, o termo consagrado é assédio moral, embora haja controvérsias sobre o uso da palavra. Para alguns autores, seria correta a designação 'perseguição', 'molestamento' ou, ainda, 'intimidação' (Thofehrn et al., 2008). No entanto, outros estudiosos utilizam o termo mais geral - violência ou, até mesmo, psicoterrorismo no trabalho (Barros, 2009). Pedroso e colaboradores (2006) ressaltam que o termo assédio moral é o que melhor expressa o fenômeno, uma vez que assediar significa cercar determinado espaço territorial para exercer domínio, característica definidora do fenômeno em discussão.

Conforme os preceitos de Hirigoyen (2008), o assédio moral é conceituado como qualquer prática abusiva, por meio de palavras, gestos, ações ou condutas, repetitivas e sistemáticas, contra a dignidade ou integridade psíquica ou física de uma pessoa, com a intenção de humilhá-la e excluí-la socialmente do contexto da atividade laboral. Contudo, independentemente da definição, o fundamental é compreender que o assédio moral caracteriza-se pelo abuso de poder de forma recorrente e prolongada (Freitas, Heloani e Barreto, 2008).

No que concerne aos tipos de assédio, podem ocorrer quatro formas distintas: horizontal, praticado por pessoas hierarquicamente do mesmo nível que a vítima; vertical ascendente, quando um superior é assediado por um ou vários subordinados, geralmente porque eles não se adequam aos padrões implantados pelo superior; vertical descendente, quando o chefe subordina de forma errônea o empregado; e o misto, aquele que envolve o 
assediador vertical, o assediador horizontal e a vítima (Gosdal e Soboll, 2009; Hirigoyen, 2008; Leite, 2012).

Evidencia-se que essa prática abusiva afeta a integridade física e psicológica do indivíduo e pode causar depressão, angústia, insegurança, insônia, falta de iniciativa, estresse, dores e disfunções no aparelho respiratório, que podem arriscar a vida da vítima (Freitas, Heloani e Barreto, 2008; Guimarães e Rimoli, 2006). Além disso, as consequências do assédio moral transcendem os prejuízos causados às vítimas, provoca efeito negativo para o empregador, a sociedade e o Estado, em virtude da queda da lucratividade e da diminuição da qualidade de vida e do elevado gasto com as enfermidades provenientes dessa prática (Frontzek, 2009; Aguiar, 2006; Monte et al., 2006).

Pesquisadores relatam que a prática do assédio moral tem sido observada de forma acentuada nos mais diversos cenários de trabalho em saúde, seja em empresa pública ou privada, sobretudo no campo da enfermagem, e pode emergir dos próprios colegas de trabalho, chefes de serviços ou de outros profissionais que compõem a equipe de saúde (Cahú et al., 2011).

No âmbito da enfermagem, as condições de trabalho, como as longas jornadas, o trabalho em turnos desgastantes - como o noturno, os domingos e os feriados - os riscos de acidentes e de doenças ocupacionais; a multiplicidade e o acúmulo de funções; a separação entre o trabalho intelectual e o manual; o controle por parte das chefias, entre outros aspectos, são características peculiares que podem favorecer a ocorrência do assédio moral no trabalho (Leite, 2012).

Nesse contexto, são necessários novos estudos a respeito do assédio moral, que possam colaborar com a visibilidade social desse problema tão frequente que afeta, de modo irreversível, a saúde do trabalhador, em particular, dos profissionais de enfermagem. Retratar o assédio moral, no ambiente de trabalho de enfermagem, principalmente no âmbito da atenção básica, demonstra a necessidade de tornar público o problema e suas consequências para a sociedade, as organizações, especialmente, para o indivíduo, visto que são incipientes as publicações científicas sobre a temática.

Em face das considerações apresentadas, o estudo teve como objetivos investigar como os profissionais de enfermagem compreendem o assédio moral, bem como identificar essas situações vivenciadas pelos profissionais dessa área, suas causas e consequências para a saúde desses trabalhadores.

\section{Material e métodos}

Trata-se de uma pesquisa exploratória, de natureza qualitativa, cujo cenário da investigação foram as unidades de saúde da família, pertencentes ao Distrito Sanitário IV, localizado na cidade de João Pessoa, na Paraíba. 
Participaram da pesquisa 16 sujeitos - 11 técnicos de enfermagem e cinco enfermeiros, selecionados por meio dos seguintes critérios de inclusão: atuar há, pelo menos, um ano na referida unidade; estar em atividade profissional durante o período de coleta de dados; e ter disponibilidade e interesse em participar da pesquisa, confirmando sua concordância com a assinatura do termo de consentimento livre e esclarecido.

O material empírico foi obtido mediante a técnica de entrevista, com base em um roteiro contendo questões relacionadas com o objetivo do estudo, utilizando-se o sistema de gravação. Convém mencionar que, para manter o anonimato dos técnicos de enfermagem inseridos no estudo, os depoimentos foram identificados pela letra ' $\mathrm{T}$ ', seguida de números de 1 a 11 . Exemplo: o primeiro técnico de enfermagem entrevistado foi codificado da seguinte maneira: T1; o segundo, T2, e assim por diante. Já os enfermeiros foram identificados pela letra ' $E$ ', seguida de números de 1 a 5 . Os dados obtidos foram trabalhados qualitativamente, por meio da análise de conteúdo proposta por Bardin (2011), que engloba um conjunto de técnicas de análise das comunicações visando a obter, com procedimentos sistemáticos e objetivos de descrição do conteúdo das mensagens, indicadores que permitam inferir conhecimentos relativos às condições de produção e recepção dessas mensagens.

Neste estudo, seguiram-se as seguintes etapas: pré-análise, que consistiu em organizar os dados coletados com base nos formulários; exploração do material, identificando-se os pontos relevantes de cada questão, com seus respectivos pontos convergentes, de acordo com o seu foco comum para, depois, agrupá-los em categorias e tratar os resultados, momento em que foram abordadas as inferências e as interpretações (Bardin, 2011).

Da análise, emergiram as seguintes categorias: Assédio moral, conceito e características na visão dos profissionais de enfermagem; Comportamentos de assédio moral experimentados por profissionais de enfermagem; e Consequências do assédio moral.

A coleta de dados ocorreu durante o período de abril a maio de 2013 e só foi iniciada após a aprovação do projeto de pesquisa pelo Comitê de Ética em Pesquisa da Faculdade de Ciências Médicas da Paraíba, conforme o CAAE 02685412.2.0000.5183. Ressalte-se que o estudo foi realizado considerando-se a resolução n. 196/96 do Conselho Nacional de Saúde, no que concerne às normas e às diretrizes regulamentadoras da pesquisa com seres humanos (Brasil, 1996).

\section{Assédio moral: conceito e características na visão dos profissionais de enfermagem}

O assédio moral é qualquer conduta abusiva, realizada com palavras, atos ou comportamentos que possam danificar a integridade física ou psíquica do 
trabalhador. Essa agressão é praticada de modo oculto, em que o assediador utiliza os pontos fracos da vítima e faz com que duvide de si mesma, visando a aniquilar suas defesas e, de tal modo, a abalar progressivamente sua autoconfiança.

O assédio moral caracteriza-se por práticas de humilhações, perseguições e ameaças nos locais de trabalho, que acontecem por meio de uma violência intencional, psicológica, sutil, dissimulada, de caráter repetitivo, prolongado, com a intenção de humilhar e excluir socialmente o trabalhador das suas atividades profissionais. É capaz de ocasionar consequências negativas para a qualidade de vida no trabalho e, por conseguinte, para a saúde do trabalhador, instituindo perdas para as organizações e a sociedade (Pedroso et al., 2006). Nesse sentido, essa prática pode ser verificada por meio de cinco atributos que a configuram, a saber: violência psicológica, exclusão social do trabalhador, humilhação, caráter repetitivo e prolongado das ações e conduta abusiva (Cahú et al., 2011).

Com base nessa premissa, observou-se que os profissionais entrevistados demonstraram conhecimento acerca da prática de assédio moral, como evidenciam os relatos a seguir:

O assédio moral pode vir de várias pessoas, de usuários para a gente, pode vir do próprio colega de trabalho, de um funcionário externo. Qualquer pessoa que atinge a nossa moral é um assediador para mim (E4).

Assédio moral é quando você ultrapassa os limites de respeito para com o seu colega, pacientes e os próprios colegas de trabalho de forma repetida e por muito tempo (T3).

Para mim é todo tipo de ação, de atitude de um indivíduo para o outro que pode atingir a moral. Tipo ofensas, através de palavras que vêm geralmente do chefe (E3).

O assédio moral é considerado quando as pessoas usam do poder do cargo, da hierarquia, para humilhar ou para submeter os pequenos no ambiente de trabalho de forma prolongado (T10).

Os trechos dos depoimentos deixam transparecer, de modo enfático, que os participantes do estudo compreendem que o assédio moral acontece no ambiente de trabalho, onde o assediador excede os limites de respeito e passa a humilhar o assediado com palavras ofensivas, desestabilizando-o. Em tal prática, as condutas aplicadas pelo agressor têm a intenção de humilhar, desrespeitar e excluir socialmente a vítima, ocasionando danos físicos e psicológicos (Avila, 2008).

Ressalta-se que, nas falas desses profissionais de enfermagem, é nítida a prevalência do tipo de assédio moral descendente, conforme se observa nestes depoimentos: 
Eu entendo por assédio moral a ação que uma pessoa exerce sobre outra, principalmente, no sentido hierárquico, no ambiente de trabalho. Alguém que é seu superior, extrapolando no direito profissional sobre a sua dignidade pessoal (T2).

É quando ocorrem situações humilhan-tes repetidas vezes do empregador sobre o empregado (T6).

O assédio vertical descendente é considerado o mais frequente e grave, em que a violência é cometida de cima para baixo, e o subordinado é agredido por um superior hierárquico ou pelo próprio empregador, sócio ou dono da empresa. Pesquisadores constatam que o assédio moral oriundo de um superior tem consequências mais graves sobre a saúde do trabalhador do que os demais tipos, porquanto a vítima, por ter um cargo inferior, sente-se mais isolada e se depara com muitas dificuldades para solucionar o problema (Cahú et al., 2012).

Outras modalidades de assédio também foram contempladas nos trechos dos depoimentos, como o assédio vertical ascendente: um superior é assediado por um ou vários subordinados; o horizontal: a agressão é realizada por um colega de trabalho do mesmo nível hierárquico e, ainda, o moral misto: envolve o assediador vertical, o assediador horizontal e a vítima (Leite, 2012).

Destarte, é notória a compreensão dos profissionais entrevistados acerca do assédio moral, um fenômeno amplamente disseminado entre enfermeiros e técnicos de enfermagem que trabalham na atenção básica, onde o assédio moral do tipo descendente é evidente.

Importa salientar que alguns profissionais confundem o assédio moral com situações de estresse, conflitos, atritos habituais, imposições profissionais, tensões e incidentes isolados, que ocorrem pontualmente e de forma assistemática, conforme evidenciado nestes relatos:

Conversas e cantadas que podem ser advindas de pacientes ou dos próprios profissionais de trabalho (El).

É a falta de respeito que alguns clientes têm em relação a alguns profissionais de saúde ou de qualquer área que possa existir (E5).

O médico vivia assediando ela direto. Ela era casada (...) às vezes até ameaçava ela, convidando-a para sair, dizendo que ela era muito bonita, dizendo palavras que até é chato a gente falar. É constrangedor mesmo (T4).

É de usuário que chega e começa a dizer o que fez e o que não fez (...) deixa a gente muito constrangida (T7). 
Ela veio, entrou com uma raiva tão grande que nem bateu na porta e foi logo pegando a receita e dizendo: olha essa... Dizendo nomes, palavrões e pegou a receita e esfregou na minha cara. Aquilo ali me deixou chocada, foi um assédio. (E2).

Alguém, por não ter o atendimento de forma rápida, começou a xingar; aí, eu senti que era um assédio moral [...] dizendo palavrões, irritado, com autonomia brava (T8).

A minha chefe usava muitas vezes do poder, da autoridade dela para me obrigar a fazer coisas que eu não queria ou que não era da minha competência fazer (T10).

Troncoso e Suazo (2005) relatam que, com as mulheres, os assédios sexual e moral se misturam facilmente, razão por que é preciso fazer a diferença entre ambos. Todavia, o assédio sexual pode tornar-se assédio moral. Nesse caso, o assédio inicia quando colegas com cargos superiores tiram proveito das mulheres trabalhadoras, marginalizando-as, humilhando-as e maltratando-as, com a finalidade, principalmente, de impedir que alcancem postos de mais responsabilidade. É imperioso compreender que determinada prática só poderá ser considerada assédio moral quando ocorrer de forma abusiva, por meio de palavras, gestos ou ações que acontecem de forma repetitiva ou sistemática, ocasionando danos contra a dignidade ou integridade física ou psíquica de uma pessoa, ameaçando seu emprego ou degradando o ambiente de trabalho (Hirigoyen, 2008).

Na visão de Leymann (1996b), o critério utilizado como parâmetro para definir a ocorrência do assédio moral é de, no mínimo, semanalmente e, pelo menos, durante seis meses. Todavia, sabe-se que a frequência e a duração do assédio moral são muito variáveis e dependem de inúmeros fatores.

Diante do exposto, observa-se que os profissionais de enfermagem que trabalham na atenção básica precisam estar atentos a essas situações, haja vista que emergem de uma conduta inofensiva e evoluem insidiosamente. Por meio delas, os episódios de ataques se multiplicam, e as vítimas são submetidas a ações hostis e degradantes, que fazem com que se sintam inferiorizadas, o que interfere sobremaneira em sua qualidade de vida.

\section{Comportamentos de assédio moral experimentados por profissionais de enfermagem}

De acordo com Caniato e Lima (2008), as ações mais contundentes do agressor podem ir desde a recusa de comunicação direta até a omissão de informações e esclarecimentos, incluindo a desqualificação de atitudes ou serviços, o isolamento, a indução ao erro e o descrédito de opiniões. Nesse sentido, 
o assédio moral pode acontecer de forma explícita, com ameaças e agressões físicas que ocorrem até mesmo de maneira leve, porém repetitiva, que constrange, persegue e humilha a vítima. Enquadram-se nessa categoria gritos, invasão da privacidade da vítima, com ligações telefônicas, e-mails, cartas, entre outras ações (Hirigoyen, 2008). Guimarães e Rimoli (2006) apontam que, nessas situações, o assediador manipula a reputação da vítima, tendo em vista que, diversas vezes, os comentários ofensivos se dirigem à competência profissional e até mesmo aos aspectos físicos e religiosos do assediado, atentando contra sua dignidade. Esses fatos foram referenciados pelos profissionais inseridos no estudo, conforme mostram os relatos a seguir:

Ela me disse: 'Cale-se! Você é a mais burra daqui porque você fala demais'. Isso diante de todos. Era uma coisa tão humilhante trabalhar ali com o apoio sempre humilhando os profissionais. Eu estava sendo vigiado o tempo todo (T1).

A empregadora se referia a minha pessoa com palavras pejorativas. Não falava comigo durante o trabalho, era como se fôssemos duas estranhas (T9).

E ela reclamou comigo, deu um grito... E eu me senti assim, muito constrangida. Se ela estivesse me chamado assim no canto, e tivesse dito (...) ela chegou em frente a todo mundo e deu aquele gritão, isso ocorria cotidianamente (T6).

Nas falas desses profissionais de enfermagem constata-se que as agressões têm como objetivo principal praticar o assédio moral, desestabilizar psicologicamente o assediado, degradar suas condições de trabalho e excluí-lo do ambiente laboral.

Os resultados aqui assinalados estão em consonância com um estudo realizado na Turquia, em que se verificou que os comportamentos mais frequentes do assédio moral, observados em profissionais de enfermagem, foram o discurso do assediador de maneira humilhante e depreciativa na frente de outras pessoas, a atribuição de culpa por fatos que não estão sob a responsabilidade profissional do assediado e ações com o objetivo de menosprezar o assediado na presença dos outros (Yildirim et al., 2007).

É importante referir que o assédio moral pode ocorrer mediante gritos, críticas, depreciação dos métodos de trabalho, banalização e fiscalização do trabalho de modo abusivo, com o fim de limitar, restringir, censurar e retirar a autonomia do ser humano (Costa, Hammerschimidt, Erdmann, 2010).

Os discursos evidenciam que as principais condutas empregadas tiveram o propósito de deteriorar as condições de trabalho e atentar contra a dignidade dos profissionais de enfermagem. Constataram-se as vivências de humilhação, constrangimento e perseguição, no ambiente de trabalho, de maneira sistemática, o que demonstra a prática do assédio moral no âmbito da atenção básica. 


\section{Consequências do assédio moral}

O assédio moral, independentemente da forma como se manifesta, tem sido apontado na literatura como uma das causas mais frequentes de estresse laboral (Yildirin e Yildirim, 2007). Tal fenômeno provoca na vítima consequências negativas, que podem ser enquadradas em três eixos sintomáticos: psicopatológicos, psicossomáticos ou comportamentais.

Os sintomas psicopatológicos estão relacionados aos transtornos mentais que ocorrem nos seres humanos, tais como: ansiedade, depressão, ciclotimia e distimias. Os transtornos de ordem psicossomática incluem os sintomas físicos, que apresentam uma origem ou uma gênese psíquica - como hipertensão arterial, ataques de asma brônquica, úlceras estomacais, enxaqueca, perda de equilíbrio (labirintite ou Síndrome de Menière), torcicolos, lombalgias, alopecia e dores musculares e articulares de origem tensional. Já os sintomas comportamentais se traduzem em reações agressivas (consigo mesmo ou com outras pessoas do convívio social), transtornos alimentares, aumento no consumo de álcool e drogas, aumento do tabagismo, disfunção sexual e isolamento social (Rouquayrol, 2003).

Nas entrevistas, os participantes do estudo confirmaram os sintomas decorrentes da prática de assédio moral descritos na literatura. Os relatos demonstram que os participantes sofriam várias consequências com a prática do assédio moral, como alguns distúrbios, principalmente de ordem psicológica, como: febre emocional, medo, tristeza, choro e depressão, conforme ilustram os depoimentos a seguir.

Eu tive uma crise (...) tive úlcera nervosa, eu ficava nervosa quando era dia de evento, dia de trabalhar porque ficava aquela tensão em cima de mim, eu tinha medo de errar (T10).

Eu chegava lá e já sentia febre emocional pelo clima pesado que era o tempo todo (T1).

Fiquei triste, pacata (...) Fiquei me sentindo arrasada, pela humilhação que passei de forma constrangedora (T8).

Gera tristeza (...) tive início de depressão por me sentir inferior. Fiquei me sentindo menosprezada porque precisava daquele emprego e sofria muita humilhação nele (T9).

Prejudicou o meu trabalho, tive pressão alta e sentia muita dor na coluna, relaciono ao ambiente pesado do meu trabalho, a toda humilhação que passei (T11). 
Em um relato de experiência, averiguou-se que, entre as respostas psicopatológicas originadas pelo assédio moral, destacaram-se: estresse, ansiedade, raiva, humilhação, medo, perda de controle e sensação de impotência (Gaffney et al., 2012).

Pesquisa com o objetivo de determinar o assédio moral vivenciado por enfermeiros que trabalham em unidades de saúde e os efeitos fisiológicos e emocionais sobre eles verificou que as reações fisiológicas mais frequentes foram o cansaço, o estresse $(72,9 \%)$, dores de cabeça $(69,5 \%)$, falta de apetite $(53,5 \%)$ e queixas gastrointestinais $(52,9 \%)$. Em relação às reações emocionais, a mais enfatizada foi a tristeza extrema, que está relacionada a condutas hostis (58,8\%) e a crises de choro (52,5\%) (Yildirim e Yildirim, 2007).

Gaffney et al. (2012) e Castellon (2011) correlacionam o assédio à diminuição da qualidade do cuidado prestado ao paciente. Nesse contexto, o paciente que depende desses profissionais (que sofrem com o assédio moral) pode estar vulnerável a vários danos decorrentes do atendimento ineficaz, visto que as habilidades cognitivas e a capacidade de se relacionar dos enfermeiros são comprometidas quando ocorre esse tipo de violência. Portanto, os indivíduos acometidos por tal prática veem prejudicado todo o contexto de sua vida pessoal. Isso se reflete como um problema social, em que os conflitos se estendem ao ambiente familiar e às relações com amigos. Indivíduos assediados podem afastar-se do seu ambiente de trabalho e, nos casos mais graves, aposentar-se precocemente, sobrecarregando o sistema previdenciário (Ferreira, 2006; Freire, 2008).

É sobremaneira relevante destacar que essa prática fragiliza os direitos humanos fundamentais, entendidos como direitos de proteção da dignidade do ser humano, em todas as suas dimensões axiológicas: o resguardo da liberdade dos direitos e das garantias individuais, das necessidades e dos direitos econômicos, sociais e culturais e a preservação dos direitos à fraternidade e à solidariedade (Cahú et al., 2011).

Conclui-se que o assédio moral acarreta sérias consequências à saúde do trabalhador e pode marcar negativamente e de maneira definitiva a vida laboral ou mesmo toda a vida de relação da pessoa assediada. Nesse caso, é preciso criar medidas de prevenção urgentes. Há que se ressaltar que tal prática é uma epidemia invisível, que resulta na falta de mobilização de recursos de todas as naturezas para o combate à violência (Xavier et al., 2008)

Portanto, os comportamentos de violência, dentro do local de trabalho, devem ser identificados precocemente, para que novas políticas públicas sejam implementadas, com a finalidade de coibir tal fenômeno, visando à melhoria da qualidade de vida dos profissionais da área da saúde, essencialmente os da enfermagem. 


\section{Considerações finais}

O presente estudo, que abordou a prática do assédio moral entre os profissionais de enfermagem da atenção básica, ressalta que o assédio moral acontece de diversas formas e que está presente nas relações de trabalho desta classe profissional.

Ficou evidente, nos depoimentos dos participantes do estudo, que tal fenômeno é disseminado entre enfermeiros e técnicos de enfermagem, apesar de alguns profissionais discernirem o conceito de assédio moral. Os trabalhadores envolvidos nesse estudo ressaltam que é nítida a prevalência do tipo de assédio moral descendente.

Outro ponto que merece destaque são as humilhações, os constrangimentos e as perseguições de forma repetitiva no ambiente de trabalho, que desestabilizam o equilíbrio físico e, principalmente, emocional da vítima, além de alterar o relacionamento com os colegas de trabalho e com os demais indivíduos. Portanto, cabe à enfermagem estar atenta às estratégias que podem ser adotadas para evitar esse sofrimento psíquico.

Nessa perspectiva, espera-se que esta pesquisa subsidie novas investigações acerca do referido tema, visto que se trata de uma prática desconhecida para muitos profissionais da área da saúde.

\section{Colaboradores}

Cristiani Garrido de Andrade e Isabelle Cristinne Pinto Costa participaram da concepção e desenho da pesquisa, análise e interpretação dos dados, redação e revisão crítica do manuscrito. Jonathas David Mendes Leão participou da concepção e desenho da pesquisa, obtenção de dados, análise e interpretação dos dados e da redação. Fabiana Medeiros de Brito participou da análise e interpretação dos dados e redação. Kamyla Félix Oliveira dos Santos e Solange Fátima Geraldo da Costa participaram da revisão crítica. 
Resumen Se tuvo como objetivo investigar cómo los profesionales de enfermería comprenden el acoso moral, así como identificar estas situaciones vividas por los profesionales de esta área, sus causas y consecuencias para la salud de estos trabajadores. Se trata de una investigación exploratoria, de carácter cualitativo, en la cual participaron 15 profesionales de enfermería que actúan en unidades de salud de la familia, de la ciudad de João Pessoa, estado de Paraíba, Brasil. La recolección de datos se llevó a cabo entre abril y mayo de 2013 y se realizó mediante entrevista grabada. Los datos fueron analizados utilizando la técnica de análisis de contenido. Del análisis del material, surgieron tres categorías: Acoso moral: concepto y características en la visión de los profesionales de enfermería; comportamientos de acoso moral experimentados por los profesionales de enfermería; y consecuencias del acoso moral. Se llegó a la conclusión de que el acoso moral está diseminado entre enfermeros y técnicos de enfermería, aun cuando algunos profesionales disciernen el concepto de esta práctica, observándose la prevalencia del tipo descendente.

Palabras clave enfermería; atención primaria; trabajo.

\section{Notas}

1 Programa de Pós-Graduação em Enfermagem, Centro de Ciências da Saúde, Universidade Federal da Paraíba, João Pessoa, Paraíba, Brasil.

$<$ cristiani_garrido@hotmail.com>

Correspondência: Rua das Acácias, 100, Miramar, CEP 58043-250, João Pessoa, Paraíba, Brasil.

2 Faculdade de Ciências Médicas da Paraíba, João Pessoa, Paraíba, Brasil.

<jonathasdmleao@hotmail.com>

3 Programa de Pós-Graduação em Enfermagem, Centro de Ciências da Saúde, Universidade Federal da Paraíba, João Pessoa, Paraíba, Brasil.

<belle_costa@hotmail.com>

4 Programa de Pós-Graduação em Enfermagem, Centro de Ciências da Saúde, Universidade Federal da Paraíba, João Pessoa, Paraíba, Brasil.

$<$ fabianabrito_@hotmail.com>

${ }^{5}$ Faculdade de Ciências Médicas da Paraíba, João Pessoa, Paraíba, Brasil.

$<$ kamylaoliveira@hotmail.com>

6 Departamento de Enfermagem, Centro de Ciências da Saúde, Universidade Federal da Paraíba, João Pessoa, Paraíba, Brasil.

$<$ solangefgc@gmail.com> 


\section{Referências}

AGUIAR, André L. S. Assédio moral: o direito à indenização pelos maus-tratos e humilhações sofridos no ambiente de trabalho. São Paulo: Editora LTr, 2006.

AVILA, Rosemari P. As consequências do assédio moral no ambiente de trabalho. $148 \mathrm{f}$. Dissertação (Mestrado em Direito) - Programa de Pós-Graduação em Direito, Universidade de Caxias do Sul, Caxias do Sul, 2008.

BARDIN, Laurence. Análise de conteúdo. Lisboa: Edições 70, 2011.

BARROS, Renato C. L. G. Assédio moral: dos efeitos e aspectos probatórios do psicoterror no ambiente de trabalho empresarial. Buscalegis, Universidade Federal da Bahia, 2009. Diponível em: <www.conpedi.org.br/ manaus/arquivos/anais/salvador/renato_da_ costa_lino_de_goes_barros.ppd $>$. Acesso em: 21 ago. 2013

BRASIL. Conselho Nacional de Saúde. Diretrizes e normas regulamentadoras sobre pesquisa envolvendo seres humanos. Resolução 196. 1996. Brasília: CNS, 1996.

BRODSKY, Carroll M. The harassed worker. Lexington, Mass: Lexington Books, 1976.

CAHÚ, Graziela R. P. et al. Assédio moral: análise de conceito na perspectiva evolucionista de Rodgers. Acta Paulista de Enfermagem, São Paulo, v. 25, n. 4, p. 555-559, 2012.

CAHÚ, Graziela R. P. et al. Produção científica em periódicos on line acerca da prática do assédio moral: uma revisão integrativa. Revista Gaúcha de Enfermagem, Porto Alegre, v. 32, n. 3, p. 611-619, 2011.

CANIATO, Angela M. P.; LIMA, Eliane C. Assédio moral nas organizações de trabalho: perversão e sofrimento. Cadernos de Psicologia Social do Trabalho, São Paulo, v. 11, n. 2, p. 177-192, 2008 .
CASTELLÓN, Angelina M. D. Violência laboral em enfermeiras: explicações e estratégias de enfrentamento. Revista Latino-Americana de Enfermagem, Ribeirão Preto, v. 19, n. 1, p. 1-8, 2011.

COSTA, Silvana S.; HAMMERSCHIMIDT, Karina S. A.; ERDMANN, Alacoque L. Assédio moral nas relações de trabalho na enfermagem: olhares possíveis a partir da complexidade. Cogitare Enfermagem, Curitiba, v. 15, n. 4, p. 749-752, 2010.

FERREIRA, João B. et al. Situações de assédio moral a trabalhadores anistiados políticos de uma empresa pública. Psicologia em Revista, Belo Horizonte, v. 12, n. 20, 2006.

FREIRE, Paula A. Assédio moral e saúde mental do trabalhador. Trabalho, Educação e Saúde, v. 6, n. 2, p. 367-380, 2008.

FREITAS, Maria E.; HELOANI, Roberto; BARRETO, Margarida. Assédio moral no trabalho. São Paulo: Cengage Learning, 2008.

FRONTZEK, Luciana G. M. Assédio moral: novos rumos da violência psicológica no trabalho. 97 f. Dissertação (Mestrado em Psicologia) - Universidade Federal de Minas Gerais, Belo Horizonte, 2009.

GAFFNEY, Donna A. et al. Making things right: nurses' experiences withworkplace bullying-a grounded theory. Nursing Research and Practice, Nova York, v. 2012, p. 1-10, 2012.

GOSDAL, Thereza C.; SOBOLL, Liz A. P. Assédio moral interpessoal e organizacional. São Paulo: Editora LTr, 2009.

GUIMARÃES, Liliana A. M.; RIMOLI, Adriana O. Mobbing (assédio psicológico) no trabalho: uma síndrome psicossocial multidimensional. Psicologia: Teoria e Pesquisa, Brasília, v. 22 , n. 2 p.183-191, 2006 
HIRIGOYEN, Marie-France. Assédio moral: a violência perversa no cotidiano. 9. ed. Rio de Janeiro: Bertrand Brasil, 2008. p. 65.

LEITE, Alice I. T. Assédio moral no âmbito hospitalar: estudo com profissionais de enfermagem. 104 f. Dissertação (Mestrado em Enfermagem) - Programa de Pós-Graduação em Enfermagem, Universidade Federal da Paraíba, João Pessoa, 2012.

LEYMANN, Heinz. Mobbing: la persécution au travail. França: Editions du Seuil, 1996a.

LEYMANN, Heinz. The content and development of mobbing at work. European Journal of Work and Organizational Psychology, v. 5, n. 2, p. 165-184, 1996 b.

MONTE, Pedro R. G. et al. Estudio piloto sobre la prevalencia del acoso psicológico (mobbing) en trabajadores de centros de aténcion a personas con discapacidad. Aletheia, Canoas, v. 23, p. 7-16, 2006.

PEDROSO, Volnei G. et al. Aspectos conceituais de assédio moral: um estudo exploratório. RAS, São Paulo, v. 8, n. 33, p. 139147, 2006.
ROUQUAYROL, Zélia M. Epidemiologia e saúde. 4. ed. Rio de Janeiro: Medsi, 2003

THOFEHRN, Maira B. et al. Assédio moral no trabalho da enfermagem. Cogitare Enfermagem, Curitiba, v. 13, n. 4, p. 597-601, 2008.

TRONCOSO, Margarita P.; SUAZO, Sandra V. Enfermeras en riesgo: violência laboral con enfoque de género. Index de Enfermería, Granada, v. 14, n. 51, p. 40-44, 2005.

XAVIER, Ana C. H. et al. Assédio moral no trabalho no setor de saúde do Rio de Janeiro: algumas características. Revista Brasileira de Saúde Ocupacional, São Paulo, v. 33, n. 117, p. 15-22, 2008.

YILDIRIM, Dilek et al. Mobbing behaviors encountered by nurse teaching staff. Nursing Ethics, v. 14, n. 4, p. 447-463, 2007.

YILDIRIN, Aytolan; YILDIRIM Dilek. Mobbing in the workplace by peers and managers: mobbing experienced by nurses working in health care facilities in Turkey and its effect on nurses. Journal of Clinical Nursing, v. 16, n. 8, p. 1.444-1.453, 2007.

Recebido em 10/09/2013

Aprovado em 23/05/2014 